\title{
Determining Methamphetamine in Urine by Molecularly Imprinted Polymer Assisted Paper Spray Ionization Mass Spectrometry
}

\author{
Talita P. de Brito, ${ }^{a}$ Deborah V. A. de Aguiar, ${ }^{a}$ Igor Pereira ${ }^{\circledR *, a}$ and Boniek G. Vaz ${ }^{\odot *, a}$ \\ ${ }^{a}$ Instituto de Química, Universidade Federal de Goiás, 74690-900 Goiânia-GO, Brazil
}

\begin{abstract}
The usefulness of molecularly imprinted polymer assisted paper spray ionization mass spectrometry (MIP-PSI-MS) for the determination of methamphetamine in urine has been demonstrated. MIP-PSI-MS is a method in which a MIP is synthesized on the surface of a paper, producing a chemically selective paper surface with molecular recognition sites for a target analyte. The analyte is extracted by the MIP substrate, which is posteriorly used for conventional PSI-MS analysis. As methamphetamine is one of the most widely used drugs of abuse in the world, it was selected to be studied in synthetic urine by the MIP-PSI-MS method. Methamphetamine was detected at higher ion signals compared to other different drugs, such as lysergic acid diethylamide (LSD) and cocaine, suggesting that MIP-PSI-MS has a chemical affinity for methamphetamine. In experiments to validate the method, a linear calibration curve was achieved with R-squared $\left(\mathrm{R}^{2}\right)>0.99$. Limit of detection (LOD) and limit of quantification (LOQ) were determined to be 0.8 and $2.8 \mu \mathrm{g} \mathrm{L} \mathrm{L}^{-1}$, respectively. Precision (relative standard deviation) and accuracy (relative error) were less than $10 \%$, and the recoveries were close to $100 \%$. The matrix effect was below $10 \%$. These data demonstrate the possibility of using MIP-PSI-MS as an analytical tool for a specific/ selective analysis of methamphetamine in forensic sciences.
\end{abstract}

Keywords: ambient mass spectrometry, paper spray ionization, molecularly imprinted polymer, methamphetamine

\section{Introduction}

Methamphetamine, a monoamine containing a methyl substituent in the amino group and possessing one chiral center, is an illicit psychostimulant often found either as a racemate or as the $(S)-(+)$-enantiomer in illegal drug sales locations. ${ }^{1}$ Methamphetamine works in the brain by increasing the concentration of some natural neurotransmitters, such as dopamine, serotonin, and norepinephrine, by releasing these compounds from storage vesicles, which results in stimulation of motivation, movement, pleasure, and reward centers. ${ }^{2,3}$ These effects can last for several hours, as the elimination half-life of this drug in humans is $10 \pm 5 \mathrm{~h} .{ }^{4}$ However, the use of this drug is also associated with several negative effects, including altered behavioral and cognitive functions, acute toxicity, renal and liver failure, tachycardia, hypertension, hyperthermia, and blood-brain barrier damage. ${ }^{5,6}$ Even with these negative consequences, methamphetamine is one of the most widely used illicit psychostimulant drugs in the world. ${ }^{7}$ Data from the World Drug Report 2019, ${ }^{8}$ which is an annual United

*e-mail: ipsigorpereira@gmail.com; boniek@ufg.br
Nations overview of the major developments in drug markets for the various categories of drugs, demonstrate that methamphetamine is predominantly used in Africa, North America, Asia, Australia, and New Zealand, and is among the most used drugs of abuse in Latin America. The report from 2017 estimates 200 tons of methamphetamine seized worldwide just in that year. Evidently, these data claim the development and application of analytical techniques capable of efficiently detecting and quantifying methamphetamine in forensic samples.

Two of the most commonly used techniques for analysis of methamphetamine in forensic science are gas chromatography coupled to mass spectrometry (GC-MS) and liquid chromatography coupled to mass spectrometry (LC-MS). ${ }^{9-11}$ Both are well-established techniques in analytical chemistry but are well known for requiring laborious sample preparation steps prior to instrumental analysis. The high time consumption, high cost, and high consumption of solvents are obstacles that have led analytical chemists to develop faster, cheaper, and more ecofriendly analytical techniques. In this sense, a family of techniques called ambient MS was developed to enable the analysis of compounds from their native environment 
with minimal or no sample preparation. ${ }^{12}$ Although tens of ambient MS methods have been reported,,$^{13}$ one of the simplest and cheapest is paper spray ionization (PSI). ${ }^{14}$ This technique is based on the deposition of a small volume of sample on the surface of a triangular paper that is typically allowed to dry for a few seconds or minutes at room temperature. Then, a high voltage is applied, a solvent is added, and droplets from the sample are electrosprayed from the tip of the paper into a mass spectrometer. The usefulness of the PSI-MS technique has been proved by its wide range of applicability, which includes the analysis of antidepressants, ${ }^{15}$ differentiation of bacteria, ${ }^{16}$ identification of drugs of abuse, ${ }^{17}$ quantification of pesticides, ${ }^{18,19}$ detection of proteins, ${ }^{20}$ and many others. ${ }^{21-24}$

Despite the wide applicability of PSI-MS, this method has limitations that are common to electrospray-based ionization methods, such as ionization suppression, low sensitivity at trace levels, and narrow dynamic range. To overcome these limitations, researchers have made a number of modifications on the triangular paper surface..$^{25-30} \mathrm{~A}$ material that can be used in paper modification approaches is the molecularly imprinted polymer (MIP). MIPs are polymers that provide a chemically selective surface by producing molecular recognition sites for a target analyte. The synthesis of MIP involves the formation of a complex between the target analyte (often called "template") and a functional monomer, with subsequent polymerization assisted by the excess of cross-linking monomer and an appropriate solvent. The polymerization is often performed in the presence of an initiator compound that is activated using ultraviolet (UV) radiation. After polymerization is complete, the template molecule is removed from the polymeric film, leaving behind recognition sites that are chemically related to the target/template molecule. ${ }^{31,32}$ Our group has demonstrated the usefulness of synthesizing MIPs on the surface of cellulose membranes and using them as substrates for PSI-MS analysis. We reported a selective extraction and enhanced analysis of human metabolites in urine, ${ }^{33}$ pesticides in fruits,,${ }^{34}$ and cocaine in oral fluid. ${ }^{35}$ In addition, methamphetamine has already been reported as a template molecule for MIP analysis by other groups using different instrumental techniques. ${ }^{36-38}$ In this sense, we consider that the coupling between MIP and PSI-MS could be useful for the determination of methamphetamine in biological fluids.

Therefore, in this work, the molecularly imprinted polymer assisted paper spray ionization mass spectrometry (MIP-PSI-MS) technique was employed for the analysis of methamphetamine in synthetic urine. The MIP was synthesized directly on the surface of a cellulose membrane that was used to extract the analyte from the urine, positioned in front of the mass spectrometer, and submitted to conventional PSI-MS analysis. The recognition sites and specificity of the method for methamphetamine were investigated by comparing the results with those obtained from the analysis of other drugs of abuse, such as cocaine and lysergic acid diethylamide (LSD). Figures of merit such as linearity, limit of detection (LOD), limit of quantification (LOQ), precision, accuracy, recovery, and matrix effect were evaluated in a tentative to validate the method.

\section{Experimental}

\section{Chemicals and materials}

High-performance liquid chromatography (HPLC) grade methanol and formic acid were acquired from J. T. Backer (Phillipsburg, USA), and analytical grade acetone was purchased from Scharlab S. L. (Sentmenat, Spain). Ultrapure water was produced using a water purification system (Master System MS2000, Gehaka, São Paulo, Brazil) with a resistivity of $18.2 \mathrm{M} \Omega \mathrm{cm}$. Methacrylic acid and ethylene glycol dimethacrylate were obtained from Sigma-Aldrich (São Paulo, Brazil), and benzophenone was acquired from Vetec Química Fina Ltda. (Rio de Janeiro, Brazil). Methamphetamine, cocaine, and LSD were provided by the Polícia Técnico-Científica (Goiânia, Goiás). Regenerated cellulose membranes containing a pore size of $0.45 \mu \mathrm{m}$, a diameter of $47 \mathrm{~mm}$, and a thickness of $160 \mu \mathrm{m}$ were acquired from Agilent (Santa Clara, USA).

\section{MIP synthesis}

MIP was synthesized according to previous works reported by our group, ${ }^{33-35}$ modifying only the template molecule. Briefly, the membrane was first washed for $4 \mathrm{~h}$ using methanol in Soxhlet. After drying under room temperature, the membrane was cut into equilateral triangles $(1 \mathrm{~cm}$ sides) and submerged for 5 min into a benzophenone solution (150 $\mathrm{mmol} \mathrm{L}^{-1}$ in acetone). The triangular membranes were transferred to Petri dishes containing a $10 \mathrm{mmol} \mathrm{L}^{-1}$ methanolic solution of methamphetamine, $50 \mathrm{mmol} \mathrm{L}^{-1}$ of methacrylic acid, and $150 \mathrm{mmol} \mathrm{L}^{-1}$ of ethylene glycol dimethacrylate. This mixture was exposed to ultraviolet (UV) irradiation for $20 \mathrm{~min}$ for the curing process. Finally, methamphetamine, non-grafted polymers, and residual initiators were removed from the membrane by Soxhlet extraction using methanol. A non-imprinted polymer (NIP) was synthesized similarly to the MIP, but without the template molecule. In total, 72 triangles (including MIP and NIP) were manufactured. 
As approximately 12 triangles can be obtained from a single membrane, a total of 6 membranes were used throughout the article. Approximately 70 triangles can be synthesized per synthesis cycle.

\section{Sample preparation}

The synthetic urine was prepared in water by using $3.333 \mathrm{~g} \mathrm{~L}^{-1}$ of urea, $0.050 \mathrm{~g} \mathrm{~L}^{-1}$ of uric acid, $0.177 \mathrm{~g} \mathrm{~L}^{-1}$ of creatinine, $1.000 \mathrm{~g} \mathrm{~L}^{-1}$ of chloride, $1.000 \mathrm{~g} \mathrm{~L}^{-1}$ of potassium, $0.025 \mathrm{~g} \mathrm{~L}^{-1}$ of phosphate, $0.300 \mathrm{~g} \mathrm{~L}^{-1}$ of sulfate, $0.025 \mathrm{~g} \mathrm{~L}^{-1}$ of calcium, $0.0167 \mathrm{~g} \mathrm{~L}^{-1}$ of magnesium, $0.167 \mathrm{~g} \mathrm{~L}^{-1}$ of sodium, $0.025 \mathrm{~g} \mathrm{~L}^{-1}$ of ammonium, and $0.167 \mathrm{~g} \mathrm{~L}^{-1}$ of carbonates. ${ }^{33,39}$

\section{MIP-PSI-MS}

The MIP-PSI-MS analysis was performed using previously described protocols. ${ }^{33,34}$ The membranes were dipped into a beaker containing desired amounts of methamphetamine dissolved in $2 \mathrm{~mL}$ of synthetic urine and stirred for $5 \mathrm{~min}$ to obtain MIP analyte extraction. Then, the membranes were removed and dried at room temperature. Each membrane was carefully held by a tweezer and dipped into a beaker containing $2 \mathrm{~mL}$ of water, making circular and vertical movements for $1 \mathrm{~min}$ to remove unbound urine components from the polymeric film. After drying under room temperature, the triangular membrane was held by a metal clip connected to the voltage source of the mass spectrometer (Figure 1). The membrane tip was positioned approximately $4 \mathrm{~mm}$ from the mass spectrometer inlet. The voltage source was turned on, and a volume of $15 \mu \mathrm{L}$ of methanol ( $0.1 \%$ formic acid) was pipetted onto the membrane to generate electrospray for MS analysis. Analyses using non-imprinted membranes (NIP) were performed to compare the results with those from the MIP membranes and determine the usefulness of the MIP approach. In addition, to investigate the specificity of MIP extraction for methamphetamine, cocaine and LSD were extracted from synthetic urine by membranes synthesized with methamphetamine and analyzed using the procedure described above.

\section{Instrumental parameters}

For qualitative and quantitative analyses, the intensity of the MS/MS product ion was employed by summing the ion current under the area of the extracted ion chromatogram (from the beginning to the fall of the analyte signal, which was approximately 0 to $1.3 \mathrm{~min}$ ). Mass spectra were obtained using a Thermo Scientific LCQ Fleet ion trap mass spectrometer (San Jose, USA). The optimized

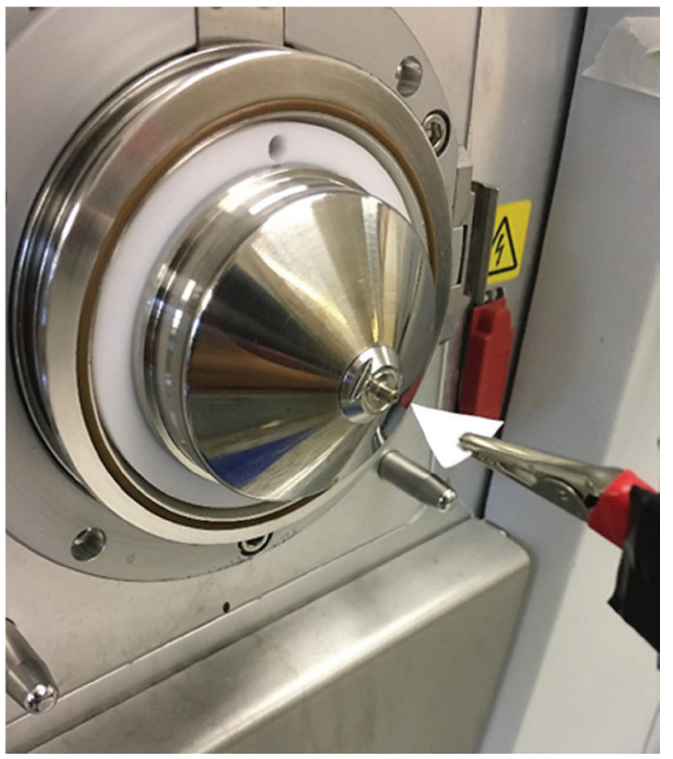

Figure 1. MIP-PSI homemade system. The metal clip holds the membrane and applies a high voltage to it, generating a spray with charged droplets that are directed to the mass spectrometer inlet for MS analysis.

instrumental parameters were as follows: positive ionization mode; spray voltage: $3.5 \mathrm{kV}$; capillary temperature: $275^{\circ} \mathrm{C}$; capillary voltage: $10 \mathrm{~V}$; tube lens: $50 \mathrm{~V}$; collision energy: 20 (manufacturer's unit); activated automatic gain control (AGC); maximum injection time: $100 \mathrm{~ms}$; microscans: 2. The mass spectra were acquired in triplicates using the Thermo Tune Plus software and were processed using the Xcalibur Analysis software package (version 2.0, Service Release 2, Thermo Electron Corporation).

\section{Analytical performance}

The calibration curve, LOD, LOQ, accuracy (relative error), precision (relative standard deviation), recovery, and matrix effect were evaluated in a tentative to validate the method. For the calibration curve, methamphetamine was dissolved in the synthetic urine, and aliquots were diluted in the same matrix to obtain concentrations of 1, 50, 100, 200, $300,400,500 \mu \mathrm{g} \mathrm{L}^{-1}$, which were analyzed in triplicate. The LOD and LOQ were calculated by the equations $3 \mathrm{sB} / \mathrm{m}$ and $10 \mathrm{sB} / \mathrm{m}$, respectively, where $\mathrm{sB}$ is the standard deviation of 10 blank measurements, and $\mathrm{m}$ is the slope of the calibration curve. The accuracy and precision were determined by using intraday $(\mathrm{n}=5)$ and interday $(\mathrm{n}=3)$ assays with concentrations at 10,300 , and $500 \mu \mathrm{g} \mathrm{\textrm {L } ^ { - 1 }}$. The accuracy was obtained by the formula $\mathrm{E}=[(\mathrm{AC}-\mathrm{NC}) / \mathrm{NC}] \times 100$, where $\mathrm{E}$ is the relative error, expressed in percentage units, $\mathrm{AC}$ is the analyzed concentration, and $\mathrm{NC}$ is the nominal concentration. The precision was calculated by the equation $\mathrm{RSD}=(\mathrm{SD} / \mathrm{AC}) \times 100$, where RSD is the relative standard deviation, expressed in percentage units, and SD is the 
standard deviation. The apparent recovery (the appropriate term for the recovery obtained from the calibration graph $)^{40}$ was determined by fortifying the samples with 10,300, and $500 \mu \mathrm{g} \mathrm{L}-1$ and was calculated by the equation $[\mathrm{AC} / \mathrm{NC}] \times 100$. The matrix effect was investigated in the presence of an interfering compound (LSD or cocaine) using analyte concentrations of $400 \mu \mathrm{g} \mathrm{L}^{-1}$ and was calculated by the equation $\mathrm{ME}=(\mathrm{SMU} / \mathrm{SIU}) /(\mathrm{SMM} / \mathrm{SIM})$, where $\mathrm{ME}$ is the matrix effect (percentage units), SMU is the signal intensity of methamphetamine in urine, SIU is the signal of the interfering compound in urine, SMM is the signal of methamphetamine in methanol, and SIM is the result of the interfering compound in methanol. ${ }^{35}$

\section{Conventional PSI-MS}

PSI-MS was carried out using cellulose membranes without MIP or NIP in order to compare the results with the MIP-PSI-MS method. The analytical parameters were exactly the same as described in the sub-sections "MIP-PSI-MS" and "Instrumental parameters", but with the difference in the sample application mode. As the cellulose membrane without MIP does not have specific recognition sites for methamphetamine, the extraction and cleaning steps of the MIP film are not necessary. Thus, for the conventional PSI-MS analysis, synthetic urine containing methamphetamine $\left(400 \mu \mathrm{g} \mathrm{L}^{-1}\right)$ was pipetted (15 $\mu \mathrm{L})$ onto the triangular membrane, which was dried under room temperature and submitted to MS analysis after the application of $15 \mu \mathrm{L}$ of methanol ( $0.1 \%$ formic acid). The experiment was performed in triplicate.

\section{Results and Discussion}

It is very well known that MS/MS experiments increase chemical specificity and improve the sensitivity of MS analysis. ${ }^{41,42}$ Thus, methamphetamine $[\mathrm{M}+\mathrm{H}]^{+}$was analyzed by MIP-PSI-MS/MS to determine the fragment ion to be monitored in posterior qualitative and quantitative analyses. Figure 2 a shows the total ion chromatogram (TIC) from a typical MIP-PSI-MS/MS analysis. Figure $2 \mathrm{~b}$ shows the MS/MS spectrum with intense fragment ions at $m / z 119$ and $m / z 91$, which correspond to the loss of methylamine and a $\beta-C-C$ cleavage, respectively (Figure 2c). ${ }^{43}$ As the $m / z \quad 150 \rightarrow 119$ transition showed the most intense fragment ion, it was used to monitor the methamphetamine concentration in synthetic urine in subsequent MIP-PSI-MS analyses.

The extraction performance of the MIP-PSI-MS technique was investigated by comparing the signal intensities from the MIP and NIP membranes. Figure 3 shows a bar graph demonstrating the huge difference between MIP and NIP signals for methamphetamine in urine $\left(400 \mu \mathrm{g} \mathrm{L}^{-1}\right)$, proving that the recognition sites were successfully synthesized on the membrane surface and that they are capable of extracting the analyte at a low concentration. A conventional PSI-MS analysis (without MIP or NIP) of methamphetamine was also performed in order to compare the results with the MIP-PSI-MS method. As shown in the third bar in Figure 3, the conventional PSI-MS analysis provided an analyte ion signal lower than the MIP-PSI-MS, probably due to the absence of a specific/ selective surface. The NIP membrane provided a lower ion signal than the conventional PSI-MS due to the cleaning step of unbound compounds, which was not performed in the conventional method. In addition, when using MIP and NIP to analyze cocaine $(\mathrm{m} / \mathrm{z}, 304 \rightarrow 182)^{35}$ and LSD $(\mathrm{m} / \mathrm{z} 324 \rightarrow 223),{ }^{44}$ the signals between both substrates were not significantly different and were quite lower than the signal of methamphetamine using the MIP membrane. This result was expected because all MIP membranes used in this experiment were synthesized using methamphetamine as the template molecule, and this compound has an obvious difference in chemical structure compared to the cocaine and LSD molecules. The active sites on the imprinted membranes were designed to provide either a specific extraction for methamphetamine or a selective extraction for a molecule structurally similar to methamphetamine (e.g., a compound containing a phenethylamine backbone). This is important because it minimizes the sampling of unwanted compounds that may be used to adulterate toxicology tests.

Posteriorly, the MIP-PSI-MS method was tentatively validated for methamphetamine in synthetic urine by determining figures of merits such as linearity, LOD, LOQ, precision, accuracy, recovery, and matrix effect. Figure S1 (Supplementary Information section) demonstrates the calibration curve constructed with methamphetamine concentrations ranging from 1 to $500 \mu \mathrm{g} \mathrm{L}{ }^{-1}$. An R-squared $\left(\mathrm{R}^{2}\right)$ above 0.99 was achieved, showing a linear relationship between the concentrations of methamphetamine extracted by MIP and the signal intensities obtained by MS analysis. In addition, the standard deviations of the measurements were less than $6 \%$, as demonstrated in the error bars in the calibration curve.

Figure S1 also shows the values of LOD and LOQ, which were determined to be 0.8 and $2.8 \mu \mathrm{g} \mathrm{L} \mathrm{L}^{-1}$, respectively. These values are within a range of concentrations often reported by works using conventional analytical techniques for analysis of methamphetamine in urine samples. For example, Chen ${ }^{44}$ reported the use of liquid-phase microextraction coupled to HPLC-UV and achieved a 

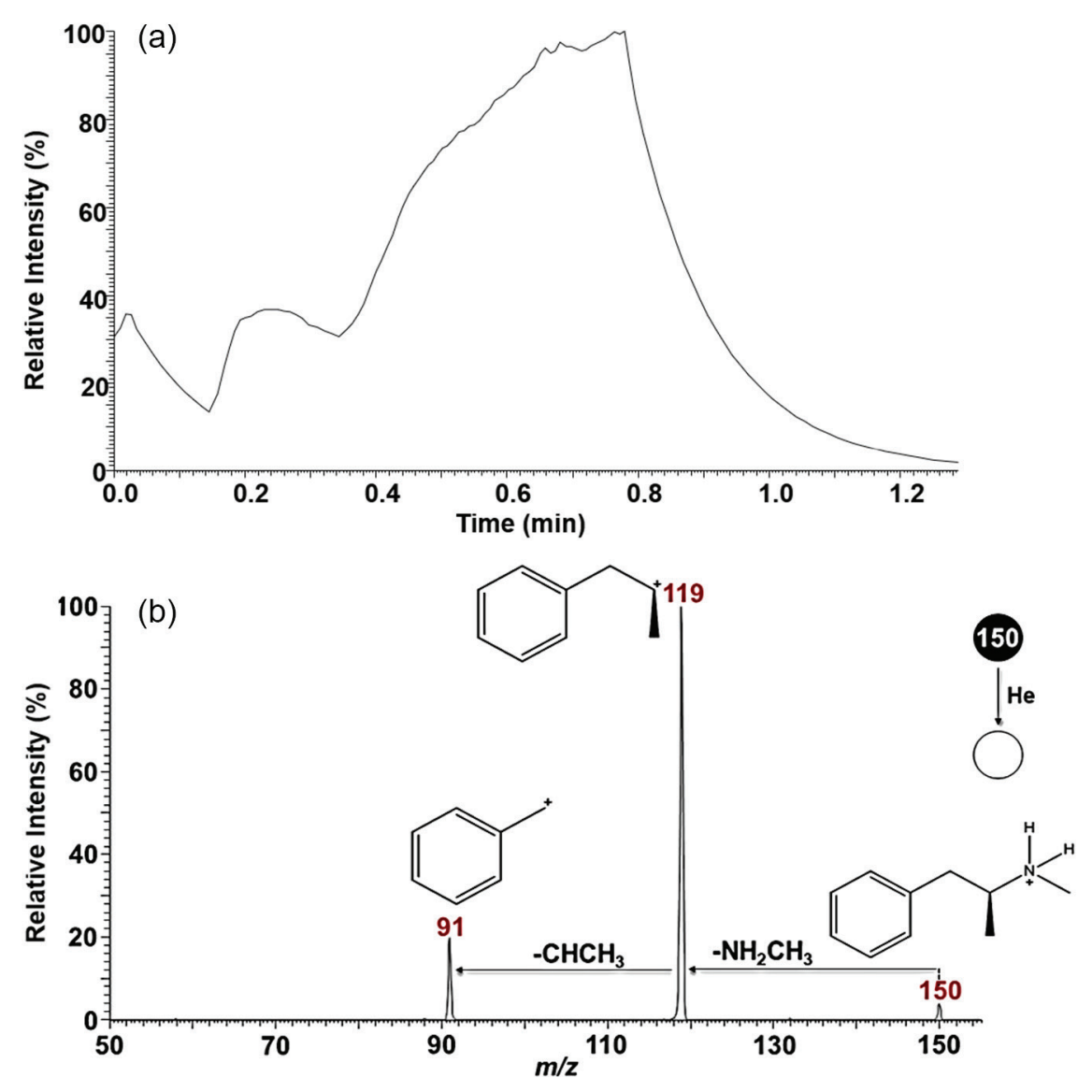

(c)<smiles>[H][Y]([H])([H])C(Cc1ccccc1)Cc1ccccc1</smiles>

Figure 2. (a) Total ion chromatogram (TIC) obtained from MIP-PSI-MS/MS analysis of methamphetamine (400 $\mu g \mathrm{~L}^{-1}$ ) in synthetic urine; (b) MS/MS spectrum from the sum of the ion current from 0 to $1.3 \mathrm{~min}$ of the TIC; (c) fragmentation routes of protonated methamphetamine $\left(\mathrm{m} / z 150[\mathrm{M}+\mathrm{H}]^{+}\right)$ leading to the fragment ions at $\mathrm{m} / \mathrm{z} 119[\mathrm{M}]^{+}$and $\mathrm{m} / \mathrm{z}, 91[\mathrm{M}]^{+}$.

LOD of $10 \mu \mathrm{g} \mathrm{L}-1$ and a LOQ of $40 \mu \mathrm{g} \mathrm{L} \mathrm{L}^{-1}$. Wang et al..$^{45}$ used LC-MS and determined LOD and LOQ values at 20 and $50 \mu \mathrm{g} \mathrm{L} \mathrm{L}^{-1}$, respectively. Shahvandi et al..$^{46}$ developed a liquid-phase microextraction method coupled to GC-MS and achieved a LOD of $1.5 \mu \mathrm{g} \mathrm{L}^{-1}$ and a LOQ of $5 \mu \mathrm{g} \mathrm{L} \mathrm{L}^{-1}$. In addition, some methods using MIP as an extraction phase also report a similar concentration range of LODs and LOQs. For example, Masteri-Farahani et al.$^{47}$ reported a LOD of $1.7 \mu \mathrm{g} \mathrm{L} \mathrm{L}^{-1}$ after the development of a nanosensor based on graphene quantum dots embedded within a MIP for subsequent methamphetamine analysis by Fouriertransform infrared spectroscopy (FTIR). Djozan et al. ${ }^{48}$ employed a molecularly imprinted-solid phase extraction combined with simultaneous derivatization and dispersive liquid-liquid microextraction with subsequent GC-FID analysis and found LOD and LOQ values of 2 and $8 \mu \mathrm{L} \mathrm{L}^{-1}$, respectively.

The precision (RSD) and accuracy (relative error) values (intraday and interday) for the MIP-PSI-MS method are demonstrated in Table 1. The assays were performed 


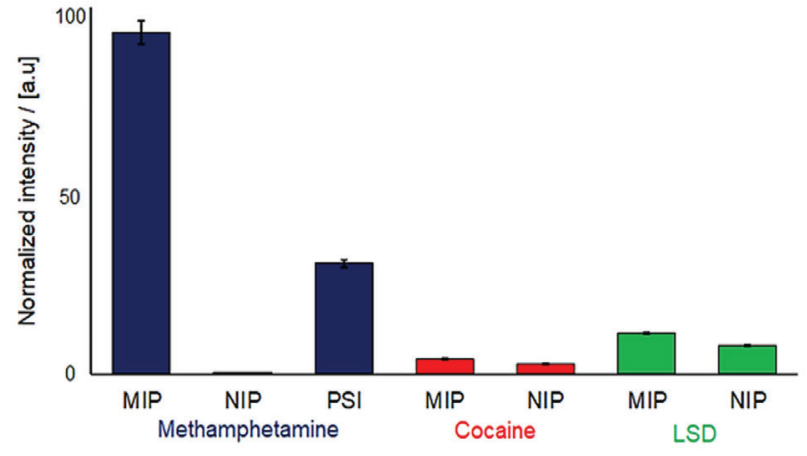

Figure 3. Bar graph of signal intensities obtained from the positive ion mode mass spectra of methamphetamine $(\mathrm{m} / \mathrm{z}, 150 \rightarrow 119)$ in synthetic urine (400 $\mu \mathrm{g} \mathrm{L}^{-1}$ ) using MIP, NIP, and conventional PSI-MS (all labeled in blue). The red bars show the analyses of cocaine $(\mathrm{m} / \mathrm{z}, 304 \rightarrow 182)$, and the green bars show the analyses of $\operatorname{LSD}(\mathrm{m} / z, 324 \rightarrow 223)$, all in synthetic urine (400 $\mu \mathrm{g} \mathrm{L}^{-1}$ ) using MIP and NIP. All MIP analyses were performed with membranes synthesized using methamphetamine as the template. Error bars show the standard deviation of triplicate measurements.

using methamphetamine concentrations at 10,300, and $500 \mu \mathrm{g} \mathrm{L} \mathrm{L}^{-1}$. The lowest values of precision and accuracy were 1.0 and $-1.1 \%$, respectively, both at $500 \mu \mathrm{g} \mathrm{L} \mathrm{L}^{-1}$ in the intraday analyses. Overall, the precision and accuracy values were below $10 \%$, which are consistent with high precision and high accuracy methods (variation should be below 20\%) for drug analysis, according to the Food and Drug Administration. ${ }^{49}$

Table 1 also shows the recovery values for the MIP-PSI-MS technique. The results were determined to be 102.0, 104.2 and $98.9 \%$ at 10,300 , and $500 \mu \mathrm{g} \mathrm{L}^{-1}$, respectively. These results are similar to those reported by recent works using well-established analytical techniques for the analysis of methamphetamine in urine. Concheiro et al. ${ }^{50}$ used liquid-liquid extraction and LC-MS and reported a recovery value of $92.1 \%$. Xu and $\mathrm{Liu}^{51}$ found a recovery of $95.6 \%$ by using dispersive liquid-liquid microextraction combined with GC-MS. Rezazadeh et al..$^{52}$ developed an electromembrane surrounded solid-phase microextraction coupled with GC-FID and achieved recoveries ranging from 97.0 to $100.9 \%$. Furthermore, ambient MS techniques employing MIP extraction also showed similar recovery results for different analytes and samples, such as for pesticides in fruit extracts (from 92.5 to $116.9 \%$ ), ${ }^{34}$ drug of abuse in oral fluid (100.5-105.3\%), ${ }^{35}$ metabolites in human urine (95.5-117.7\%), ${ }^{33}$ environmental contaminants in water and fish samples (92-113\%), ${ }^{53}$ and macrolide antibiotics in honey and milk samples (73.4-98.1\%)..$^{54}$

The matrix effect was investigated by analyzing methamphetamine in the presence of LSD and cocaine, which were the interfering compounds, and the results were determined to be 4.1 and $9.6 \%$, respectively. This experiment suggests that the MIP-PSI-MS method is capable of successfully analyzing methamphetamine in urine contaminated with other drugs of abuse, which may be a typical case in forensic samples.

\section{Conclusions}

The applicability of MIP-PSI-MS for the analysis of methamphetamine in synthetic urine was demonstrated. By synthesizing a molecularly imprinted polymer onto a cellulose membrane and using it as a substrate for PSI-MS, methamphetamine was detected at higher ion signals compared to other different drugs, such as LSD and cocaine. These data suggest that the MIPPSI-MS method has the ability to specifically extract methamphetamine or other structurally similar molecules, but has a little chemical affinity for different compounds. The investigation of the analytical performance of the method was successfully demonstrated by achieving a linear calibration curve with $\mathrm{R}^{2}>0.99$, and LOD and LOQ at 0.8 and $2.8 \mu \mathrm{g} \mathrm{L}^{-1}$, respectively, which are values similar to those often reported by studies using conventional analytical techniques. In addition, the values of precision (relative standard deviation) and accuracy (relative error) were below $10 \%$, which suggests that MIP-PSI-MS is a validated method, according to regulatory agencies for method development and validation. Recoveries were close to $100 \%$, similar to other analytical methods using MIP as the phase extraction. The results of the matrix effect were below $10 \%$ in the presence of other drugs, such as LSD and cocaine, suggesting that the method can be used for the analysis of methamphetamine in urine containing other drugs of abuse.

An extremely important point in the current protocol is the possibility of reusing the MIP membranes, which

Table 1. Values of precision, accuracy, and recovery obtained from the MIP-PSI-MS analysis of methamphetamine in synthetic urine

\begin{tabular}{|c|c|c|c|c|c|}
\hline \multirow[b]{2}{*}{ Concentration / $\left(\mu \mathrm{g} \mathrm{L}^{-1}\right)$} & \multicolumn{2}{|c|}{ Precision / \% } & \multicolumn{2}{|c|}{ Accuracy / \% } & \multirow[b]{2}{*}{ Recovery / \% } \\
\hline & $\begin{array}{c}\text { Intraday } \\
(\mathrm{n}=5)\end{array}$ & $\begin{array}{c}\text { Interday } \\
(\mathrm{n}=3)\end{array}$ & $\begin{array}{c}\text { Intraday } \\
(\mathrm{n}=5)\end{array}$ & $\begin{array}{c}\text { Interday } \\
(\mathrm{n}=3)\end{array}$ & \\
\hline 10 & 9.5 & 3.2 & 1.7 & 1.6 & 102.0 \\
\hline 300 & 2.1 & 1.5 & 4.2 & 3.7 & 104.2 \\
\hline 500 & 1.0 & 1.1 & -1.1 & -1.6 & 98.9 \\
\hline
\end{tabular}


would make the method much cheaper. To do so, the entire amount of analyte that was sequestered by the MIP recognition sites needs to be removed from the polymeric film. This can be achieved by cleaning the membranes with an appropriate solvent (e.g., methanol, water, or a mixture of both) using Soxhlet extraction. Then, the membranes should be analyzed to ensure that there is no remaining content of the analyte. However, although this is a viable procedure, we have not evaluated this hypothesis in this work, but it will certainly be evaluated in future works. Another very important point is the possibility of using real urine samples. Although the current protocol has been well demonstrated for synthetic urine, its performance in the analysis of methamphetamine in real urine samples still needs to be demonstrated. This can be achieved by modifying some key parameters (if necessary) such as the time for extracting the analyte by MIP or the cleaning procedure (e.g., the solvent or the cleaning time) for removing the urine constituents from the polymeric film. Nevertheless, the optimized values achieved in the current work will certainly be useful to find the best conditions for methamphetamine in real samples. Therefore, we can conclude that this paper indicates the potential use of the MIP-PSI-MS technique in forensic sciences and that this study could be extended to the determination of methamphetamine in real urine samples, in addition to other biological fluids and forensic specimens.

\section{Supplementary Information}

Supplementary data are available free of charge at http://jbcs.sbq.org.br as PDF file.

\section{Acknowledgments}

The authors thank the Brazilian Federal Agency for Support and Evaluation of Graduate Education (CAPES) and the Brazilian National Council for Scientific and Technological Development (CNPq) for research funding.

\section{References}

1. Abbruscato, T. J.; Trippier, P. C.; ACS Chem. Neurosci. 2018, 9, 2373.

2. Rothman, R. B.; Baumann, M. H.; Eur. J. Pharmacol. 2003, 479, 23.

3. Kish, S. J.; CMAJ 2008, 178, 1679.

4. Schepers, R. J.; Oyler, J. M.; Joseph Jr., R. E.; Cone, E. J.; Moolchan, E. T.; Huestis, M. A.; Clin. Chem. 2003, 49, 121.

5. Krasnova, I. N.; Cadet, J. L.; Brain Res. Rev. 2009, 60, 379.

6. Northrop, N. A.; Yamamoto, B. K.; Front. Neurosci. 2015, 9, 69.
7. Liang, Q.; Yuan, T.; Cao, X.; He, H.; Yang, J.; Yuan, J.; Gen. Psychiatry 2019, 32, e100019.

8. https://wdr.unodc.org/wdr2019, accessed in August 2020.

9. Pizzolato, T. M.; de Alda, M. J. L.; Barceló, D.; TrAC, Trends Anal. Chem. 2007, 26, 609.

10. Vogliardi, F.; Tucci, M.; Stocchero, G.; Ferrara, S. D.; Favretto, D.; Anal. Chim. Acta 2015, 857, 1.

11. Zaitsu, K.; Hayashi, Y.; Kusano, M.; Tsuchihashi, H.; Ishii, A.; Drug Metab. Pharmacokinet. 2016, 31, 21.

12. Cooks, R. G.; Ouyang, Z.; Takats, Z.; Wiseman, J.; Science 2006, 311, 1566.

13. Feider, C. L.; Krieger, A.; DeHoog, R. J.; Eberlin, L. S.; Anal. Chem. 2019, 91, 4266.

14. Liu, J.; Wang, H.; Manicke, N. E.; Lin, J.-M.; Cooks, R. G.; Ouyang, Z.; Anal. Chem. 2010, 82, 2463.

15. de Oliveira, F. M.; Scheel, G. L.; Augusti, R.; Tarley, C. R. T.; Nascentes, C. C.; Anal. Chim. Acta 2020, 1106, 52.

16. Chamberlain, C. A.; Rubio, V. Y.; Garrett, T. J.; Anal. Chem. 2019, 91, 4964.

17. Fedick, P. W.; Pu, F.; Morato, N. M.; Cooks, R. G.; J. Am. Soc. Mass Spectrom. 2020, 31, 735.

18. Pereira, I.; Rodrigues, S. R. M.; de Carvalho, T. C.; Carvalho, V. V.; Lobón, G. S.; Bassane, J. F. P.; Domingos, E.; Romão, W.; Augusti, R.; Vaz, B. G.; Anal. Methods 2016, 8, 6023.

19. Moura, A. C. M.; Lago, I. N.; Cardoso, C. F.; Nascimento, A. R.; Pereira, I.; Vaz, B. G.; Food Chem. 2020, 310, 125938.

20. Wichert, W. R. A.; Dhummakupt, E. S.; Zhang, C.; Mach, P. M.; Bernhards, R. C.; Glaros, T.; Manicke, N. E.; J. Am. Soc. Mass Spectrom. 2019, 30, 1406.

21. da Silva, L. C.; Pereira, I.; de Carvalho, T. C.; Filho, J. F. A.; Romão, W.; Vaz, B. G.; Anal. Methods 2019, 11, 999.

22. Pereira, I.; de Carvalho, T. C.; Romão, W.; Filgueiras, P. R.; Laviola, B. G.; Rodrigues, C. M.; Abdelnur, P. V.; Vaz, B. G.; J. Braz. Chem. Soc. 2017, 28, 1461.

23. Lin, C. H.; Liao, W. C.; Chen, H. K.; Kuo, T. Y.; Bioanalysis 2014, 6, 199.

24. Frey, B. S.; Damon, D. E.; Badu-Tawiah, A. K.; Mass Spectrom. Rev. 2019, 2019, 336.

25. Carvalho, T. C.; Tarso, P. G.; Campanha, R. B.; Abdelnur, P. V.; Romão, W.; Coltro, W. K. T.; Vaz, B. G.; Analyst 2016, 141, 1707.

26. Dhummakupt, E. S.; Carmany, D. O.; Mach, P. M.; Tovar, T. M.; Ploskonka, A. M.; Demond, P. S.; DeCoste, J. B.; Glaros, T.; ACS Appl. Mater. Interfaces 2018, 10, 8359.

27. Dulay, M. T.; Zare, R. N.; Rapid Commun. Mass Spectrom. 2017, 31, 1651.

28. Song, X.; Chen, H.; Zare, R. N.; Anal. Chem. 2018, 90, 12878.

29. Ji, J.; Nie, L.; Liao, L.; Du, R.; Liu, B.; Yang, P.; J. Chromatogr. B: Anal. Technol. Biomed. Life Sci. 2016, 1015, 142.

30. Liu, J.; He, Y.; Chen, S.; Ma, M.; Yao, S.; Chen, B.; Talanta 2017, 166, 306. 
31. Martín-Esteban, A.; TrAC, Trends Anal. Chem. 2013, 45, 169.

32. Zaidi, S. A.; Mater. Sci. Energy Technol. 2020, 3, 72.

33. Mendes, T. P.; Pereira, I.; Ferreira, M. R.; Chaves, A. R.; Vaz, B. G.; Anal. Methods 2017, 9, 6117.

34. Pereira, I.; Rodrigues, M. F.; Chaves, A. R.; Vaz, B. G.; Talanta 2018, $178,507$.

35. Tavares, S. L.; Carvalho, T. C.; Romão, W.; Vaz, B. G.; Chaves, A. R.; J. Am. Soc. Mass Spectrom. 2018, 29, 566.

36. Djozan, D.; Farajzadeh, M. A.; Sorouraddin, S. M.; Baheri, T.; Chromatographia 2011, 73, 975.

37. Arenas, L. F.; Ebarvia, B. S.; Sevilla III, F. B.; Anal. Bioanal. Chem. 2010, 397, 3155.

38. Djozan, D.; Farajzadeh, M. A.; Sorouraddin, S. M.; Baheri, T.; Microchim. Acta 2012, 179, 209.

39. Dbira, S.; Bensalah, N.; Cañizares, P.; Rodrigo, M. A.; Bedoui, A.; J. Electroanal. Chem. 2015, 744, 62.

40. Burns, D. T.; Danzer, K.; Townshend, A.; Pure Appl. Chem. 2002, 74, 2201.

41. Cooks, R. G.; Busch, K. L.; Glish, G. L.; Science 1983, 222, 273.

42. Hoffmann, E.; Stroobant, V.; Mass Spectrometry: Principles and Applications, $3^{\text {rd }}$ ed.; John Wiley \& Sons: Chichester, England, 2007.

43. Bijlsma, L.; Sancho, J. V.; Hernández, F.; Niessen, W. M. A.; J. Mass Spectrom. 2011, 46, 865.
44. Chen, X.; Chromatographia 2015, 78, 515.

45. Wang, T.; Shen, B.; Shi, Y.; Xiang, P.; Yu, Z.; Forensic Sci. Int. 2015, 246, 72 .

46. Shahvandi, S. K.; Banitaba, M. H.; Ahmar, H.; Talanta 2018, 184, 103.

47. Masteri-Farahani, M.; Mashhadi-Ramezani, S.; Mosleh, N.; Spectrochim. Acta, Part A 2020, 229, 118021.

48. Djozan, D.; Farajzadeh, M. A.; Sorouraddin, S. M.; Baheri, T.; J. Chromatogr. A 2012, 1248, 24.

49. Food and Drug Administration (FDA); Bioanalytical Method Validation Guidance for Industry, 2018, available at https:// www.fda.gov/media/70858/download, accessed in August 2020.

50. Concheiro, M.; Simões, S. M. S. S.; Quintela, O.; de Castro, A.; Dias, M. J. R.; Cruz, A.; López-Rivadulla, M.; Forensic Sci. Int. 2007, 171, 44.

51. Xu, F.; Liu, L.; Forensic Sci. Res. 2017, 4, 188.

52. Rezazadeh, M.; Yamini, Y.; Seidi, S.; J. Chromatogr. A 2015 , 1396, 1.

53. Huang, Y.; Ma, Y.; Hu, H.; Guo, P.; Miao, L.; Yang, Y.; Zhang, M.; RSC Adv. 2017, 7, 52091.

54. Liu, Y.; Yang, Q.; Che, X.; Song, Y.; Wu, Q.; Yang, Y.; He, L.; Talanta 2019, 204, 238.

Submitted: May 11, 2020

Published online: September 2, 2020 